\title{
Modified Frailty Index Independently Predicts Postoperative Pulmonary Infection in Elderly Patients Undergoing Radical Gastrectomy for Gastric Cancer
}

\author{
Yongsheng Meng \\ Pengfei Zhao \\ Rong Yong
}

Department of Anesthesiology, Taizhou People's Hospital, Taizhou, Jiangsu,

People's Republic of China
Correspondence: Rong Yong Department of Anesthesiology, Taizhou People's Hospital, No.366, Taihu Road, Taizhou Pharmaceutical High-Tech Zone, Taizhou, 225300, Jiangsu Province,

People's Republic of China

Email tz_13423359|@I26.com
Background: Pulmonary infection is one of the most common postoperative complications after radical gastrectomy for gastric cancer (GC) and is associated with a poorer prognosis. This study aimed to investigate potential predictive factors for pulmonary infection in elderly GC patients.

Methods: This study retrospectively enrolled 346 elderly GC patients undergoing elective radical gastrectomy between January 2017 and December 2020. Pulmonary infection within postoperative 30 days was set as the primary observational endpoint. The baseline demographic, clinicopathological, and laboratory data were compared between patients with or without pulmonary infection. ROC curves were plotted to evaluate the cut-off and predictive values of factors. Binary univariate and multivariate logistic regression analyses were employed to determine risk factors for postoperative pulmonary infection.

Results: Of the enrolled 346 patients, pulmonary infection was observed in 51 patients within postoperative 30 days, with an incidence of $14.7 \%$. mFI was a significant predictor for pulmonary infection by ROC curve analysis (AUC: $0.770, \mathrm{P}<0.001$ ). Moreover, preoperative $\mathrm{mFI}$ was the only independent risk factor for pulmonary infection (OR: $2.72,95 \% \mathrm{CI}$ : $2.02-3.31, \mathrm{P}=0.011$ ) by univariate and multivariate logistic regression analyses.

Conclusion: Our study indicates that $\mathrm{mFI}$ independently predicts pulmonary infection in elderly GC patients.

Keywords: gastric cancer, elderly, radical gastrectomy, postoperative pulmonary infection, modified frailty index

\section{Introduction}

The incidence of gastric cancer (GC) is gradually decreasing worldwide; however, it is relatively high in Asia. ${ }^{1}$ In China, the incidence and mortality of GC both rank third among all the malignancies. ${ }^{2}$ Until now, surgical resection is the mainstay treatment and only curative modality for GC. ${ }^{3}$ The high incidence of postoperative complications after radical resection is a major contributor to the poor prognosis, ${ }^{4}$ with an estimated incidence ranging from $12.0 \%{ }^{5}$ to $34.4 \% .{ }^{6}$ Pulmonary infection is one of the most common postoperative complications after radical gastrectomy, and it is associated with a prolonged hospital stay, and increased morbidity and mortality rates. ${ }^{7,8}$ Thus, it is essential to determine risk factors associated with pulmonary infection in elderly GC patients. 
Frailty is widely recognized as an impaired physical response to stress and it is highly prevalent with increasing age. ${ }^{9}$ Moreover, frailty is associated with increased vulnerability to adverse health outcomes after surgical conditions, including prolonged hospitalization and increased mortality. ${ }^{10}$ Until now, no consensus for the definition of frailty has been made. The definitions of frailty varied in different studies, as synonymous with advanced old age, ${ }^{11}$ comorbidity, ${ }^{12}$ or disability. ${ }^{13}$ Increasingly, frailty is widely recognized as a biologic syndrome of cumulative declines of multiple physiologic systems, resulting in decreased energy reserve, cognition, physical ability, resistance to stressors, and increased vulnerability to adverse outcomes. ${ }^{14,15}$ As reported by previous studies, frailty is defined as a clinically state of increased vulnerability, which is induced by aging-associated decline in function and reserve across multiple physiologic systems. ${ }^{16}$ Fried et al defined frailty as a condition meeting 3 of the 5 phenotypic criteria including unintentional weight loss, exhaustion, low physical activity, slowness, and weakness. ${ }^{10}$ However, the modified frailty index (mFI) containing 11 variables based on National Surgical Quality Improvement (NSQIP) is one of the most commonly used measurements. ${ }^{17}$ Recently, mFI has attracted a lot of attention due to the gradually increasing aging population. Previous studies have indicated $\mathrm{mFI}$ as a predictor for morbidity and mortality among various surgical cohorts. ${ }^{18}$ In addition, a recent study by McChesney et al identified that mFI could predict postoperative outcomes in patients undergoing radical pelvic surgery. ${ }^{19}$ Moreover, mFI was also an effective predictor of mortality in patients with brain tumor ${ }^{20}$ and readmission after colorectal surgery for high-risk patients. ${ }^{21}$ However, the correlation between pulmonary infection and $\mathrm{mFI}$ remains unknown. This study was designed to investigate the predictive value of $\mathrm{mFI}$ for pulmonary infection in elderly GC subjects undergoing radical gastrectomy. This study focused on the association between frailty and pulmonary infection. Our results highlighted $\mathrm{mFI}$ as an independent risk factor for pulmonary infection in elderly GC patients. A recent single-center prospective cohort study by Aceto et $\mathrm{al}^{22}$ identified the predictive power of $\mathrm{mFI}$ for postoperative pulmonary complications in elderly subjects after major abdominal surgery, which was quite in accordance with our results. Collectively, our results provide a potential useful predictor for pulmonary infection in elderly.

\section{Materials and Methods}

\section{Patients}

This was a retrospective cohort study carried out at the Department of anesthesiology, Taizhou People's Hospital with the approval of the ethics committee of our hospital. Elderly GC patients who were scheduled for elective radical gastrectomy were consecutively enrolled between January 2017 and December 2020. The inclusion criteria were as follows: 1) age between 65 and 85 years; 2) American Society of Anesthesiologists (ASA) grade II and III; 3) resectable GC with pathological support; 4) with a follow-up for at least postoperative 30 days; 5) with complete clinicopathologic data. The exclusion criteria were as follows: 1) with other malignancies, or distant metastasis; 2) with preoperative chemoradiotherapy; 3) combined abdominal and thoracic surgery; 4) underwent emergency surgeries due to complications; 5) lost to follow up. All the enrolled patients should provide signed informed consent.

\section{Clinical Data Collection}

All the enrolled patients underwent the same perioperative management by the same surgical and anesthetic group. Abdominal computed tomography (CT), gastroscope, $\mathrm{X}-$ ray or $\mathrm{CT}$ of the chest, and laboratory examination were routinely performed for patients prior to surgery. The gastrectomy and lymphadenectomy were performed based on the Japanese gastric cancer treatment guidelines. $^{23}$ Enrolled patients received secondgeneration cephalosporin for 3-5 days as peri-operative prophylactic antibiotic treatment.

Data were collected as follows: 1) baseline demographic data, including age, gender, body mass index (BMI), American Society of Anaesthesiologists (ASA) physical status, smoking status; 2) clinicopathological data, including the extent of gastrectomy, surgical approach, the extent of lymph node dissection, duration of operation, estimated blood loss, histopathological grade, pathological stage, intra-operative blood transfusion, intensive care unit (ICU) admission, neutrophil-lymphocyte ratio (NLR), controlling nutrition status (CONUT), and mFI; 3) laboratory data, including hemoglobin, white blood cell, albumin, creatinine, urea, Creactive protein (CRP), and tumor necrosis factor (TNF$\alpha$ ). The histopathological grade and pathological stage were defined according to the 7th edition of the International Union Against Cancer (UICC) TNM classification. Laboratory examinations were performed using 
the obtained peripheral venous blood samples on the surgery day. As described by previous study, ${ }^{24}$ CONUT was calculated using serum albumin, lymphocyte, and total cholesterol level. In addition, the cut-off value of CONUT was set at 3 based on the previous report. ${ }^{24}$

\section{Definitions and Outcomes}

According to previous report, ${ }^{25} \mathrm{mFI}$ was evaluated using 11 preoperative items, including diabetes mellitus, congestive heart failure, hypertension requiring medication, transient ischemic attack or cerebrovascular accident, Functional status 2 (not independent), myocardial infarction, peripheral vascular disease or rest pain, cerebrovascular accident with neurological deficit, chronic obstructive pulmonary disease (COPD) or pneumonia, percutaneous coronary intervention (PCI), prior cardiac surgery, or angina, and impaired sensorium. One positive point was assigned for each of the 11 items (with the presence or history), and $\mathrm{mFI}$ was calculated by dividing positive points by 11 . The primary observational endpoint was set as the development of pulmonary infection within postoperative 30 days. As described by previous reports, postoperative pulmonary infection was defined based on new or progressive radiographic infiltrate, bacterial sputum cultures, plus two or more of the following: antibiotic treatment, temperature $>38^{\circ} \mathrm{C}$, leukocytosis (WBC $>12$ $\mathrm{x} 10^{9} / \mathrm{L}$ ) or leucopenia (WBC count $<4 \times 10^{9} / \mathrm{L}$ ), and/or purulent secretions. ${ }^{26,27}$ Enrolled patients were categorized into pulmonary infection and non-pulmonary infection groups, based on the presence of pulmonary infection within postoperative 30 days.

\section{Statistical Analysis}

The statistical analysis was conducted using SPSS 22.0 (SPSS Inc., Chicago, IL, USA) and GraphPad Prism 8.0 (GraphPad Inc., CA, USA). Continuous variables are expressed as mean with standard deviations (SD), while numerous variables as number (n) with percentage. Chisquare test, Fisher exact, Student's $t$-test, and Mann Whitney $U$-test were used for data analyses as appropriate. ROC curves were plotted to evaluate the cut-off and predictive values of factors. Binary univariate and multivariate logistic regression analyses were employed to determine risk factors for postoperative pulmonary infection using the "Enter" method. Multicollinearity analysis was performed among potential risk factors in the logistic regression model. A two-sided $\mathrm{P}$ value $<0.05$ was considered statistically significant.

\section{Results}

As showcased in Figures 1, 405 elderly GC patients were initially enrolled according to our inclusion criteria. Thereafter, 59 were excluded following exclusion criteria and a total of 346 patients were finally included in data analysis. The mean age of all the patients was calculated to be 73.7 years and the majority of patients were males $(67.9 \%, 235 / 346)$. Of the enrolled 346 patients, pulmonary infection was observed in 51 patients within postoperative 30 days, with an incidence of $14.7 \%$ (51/346). The demographics and clinical characteristics associated with pulmonary infection are summarized in Table 1. No significant differences between patients with or without postoperative pulmonary infection were observed in terms of gender, BMI, type of operation, reconstruction method, oesophageal reflux, extent of lymph node dissection, estimated blood loss, histopathological grade, pathological stage, and ICU admission ( $\mathrm{P}>0.05)$. Patients with an older age $(\mathrm{P}=0.002)$, higher ASA physical status $(\mathrm{P}=$ $0.017)$, longer duration of operation $(P=0.014)$, and higher CONUT score $(\mathrm{P}=0.023)$ were more likely to develop pulmonary infection after surgery. Moreover, patients with the presence of current smoking habits $(\mathrm{P}=$ $0.039)$, intra-operative blood transfusion $(\mathrm{P}=0.020)$, and operation via laparotomy $(\mathrm{P}=0.016)$ were significantly more susceptible to pulmonary infection. Besides, patients who developed pulmonary infection showed a significantly higher percentage of high $\mathrm{mFI}$ level $(\geq 0.225)$ when comparing with those without pulmonary infection $(\mathrm{P}<0.001)$. In addition, the most common positive items in $\mathrm{mFI}$ were diabetes mellitus and hypertension (see Figure 2).

Laboratory data associated with pulmonary infection are displayed in Table 2. Patients with higher preoperative CRP ( $P=0.012)$ and lower albumin levels $(P=0.016)$ were also associated with increased risks of pulmonary infection. There was no significant difference between the two groups concerning hemoglobin, white blood cell, creatinine, urea, and TNF- $\alpha(\mathrm{P}>0.05)$.

To assess the predictive values of continuous variables for pulmonary infection, we generated ROC curves. As layout in Figure 3, age (AUC: 0.611, $\mathrm{P}=0.0012$ ), $\mathrm{mFI}$ (AUC: $0.770, \mathrm{P}<0.001$ ), and CRP (AUC: 0.594, $\mathrm{P}=$ 0.032) were three predictors for pulmonary infection. Based on the cut-off values calculated by ROC curves, the five continuous variables were categorized into high and low expression groups. Subsequently, potential risk factors $(\mathrm{P}<0.05$ in Tables 1 and 2$)$ were enrolled into 


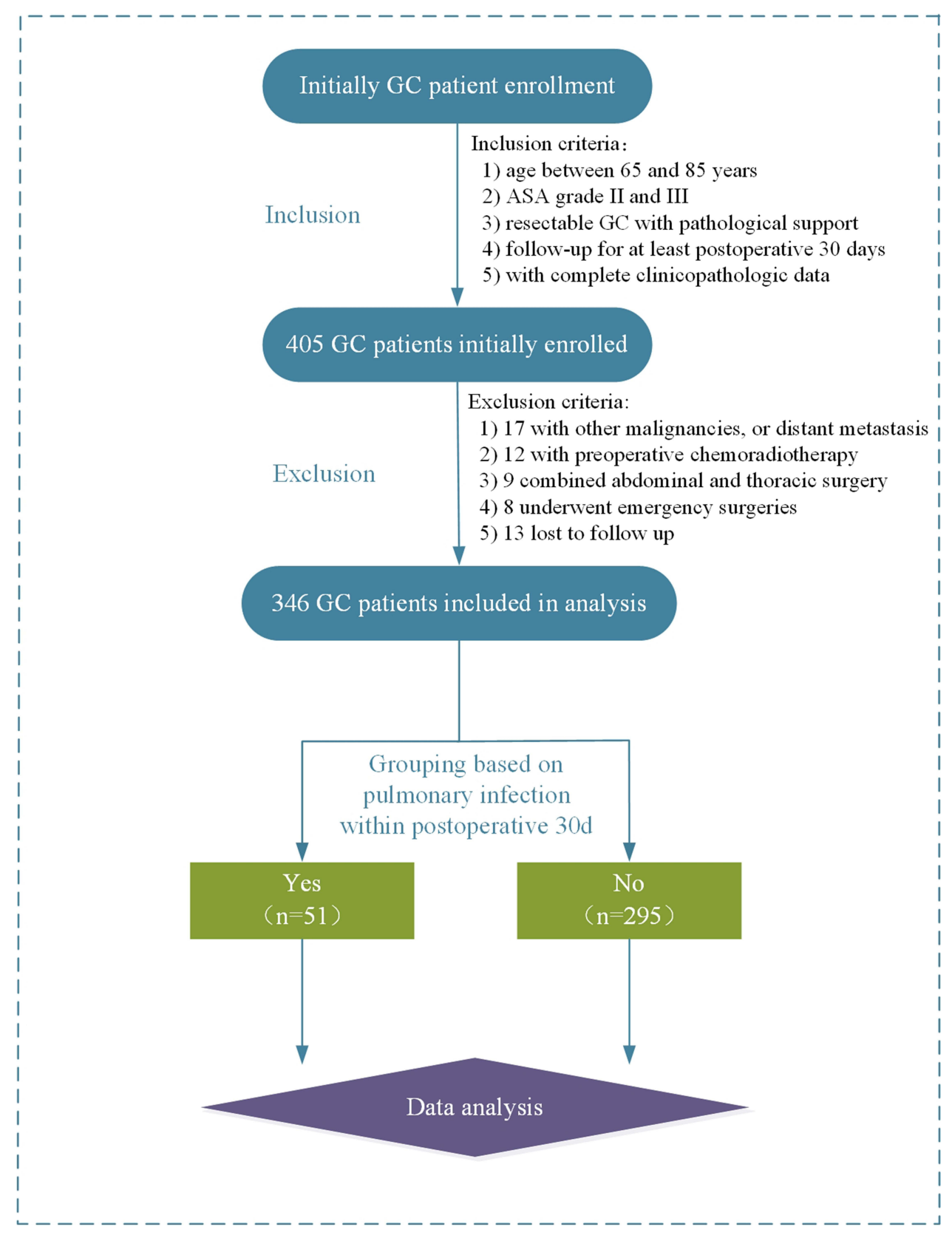

Figure I The flow chart.

Abbreviation: GC, gastric cancer.

the univariate logistic regression models. As shown by the forest plot in Figure 4, age ( $\geq 73.5$ years), ASA grade III, current smoking habit, $\mathrm{mFI}(\geq 0.225)$, and CRP ( $\geq 8.0 \mathrm{mg}$ ) L) were six potential risk factors for pulmonary infection. These five factors with $\mathrm{P}<0.05$ in univariate analysis were further included in the multivariate analysis. The results indicated that preoperative $\mathrm{mFI}(\geq 0.225)$ was the only independent risk factor for pulmonary infection (OR: 2.72, 95\% CI: 2.02-3.31, P = 0.011, see Figure 5).

\section{Discussion}

In this retrospective study including 346 elderly GC patients who underwent radical gastrectomy, the incidence of postoperative pulmonary infection was $14.7 \%$, which was quite similar to the $13.4 \%$ by previously published report. ${ }^{28}$ Patients who suffered from pulmonary infection were associated with a higher rate of intensive care and mortality, and longer hospital stay than those without pulmonary infection. Considering the adverse impact of 
Table I Demographics and Clinical Characteristics Associated with Pulmonary Infection in Elderly GC Patients After Radical Gastrectomy

\begin{tabular}{|c|c|c|c|}
\hline \multirow[t]{2}{*}{ Variables } & \multicolumn{2}{|c|}{ Pulmonary Infection } & \multirow[t]{2}{*}{$P$-value } \\
\hline & Yes $(n=51)$ & No $(n=295)$ & \\
\hline Age (year) & $75.1 \pm 3.8$ & $73.5 \pm 3.2$ & $0.002 *$ \\
\hline Gender, n (\%) & - & - & 0.443 \\
\hline Male & $37(72.5)$ & $198(67.1)$ & - \\
\hline Female & $14(27.5)$ & $97(32.9)$ & - \\
\hline BMI $\left(\mathrm{kg} / \mathrm{m}^{2}\right)$ & $22.2 \pm 2.1$ & $21.9 \pm 2.0$ & 0.327 \\
\hline ASA physical status, $n(\%)$ & - & - & $0.017^{*}$ \\
\hline II & $22(43.1)$ & $180(61.0)$ & - \\
\hline III & $29(56.9)$ & $115(39.0)$ & - \\
\hline Current smoker, n (\%) & $17(33.3)$ & $60(20.3)$ & $0.039 *$ \\
\hline Type of operation, $n(\%)$ & - & - & 0.891 \\
\hline Total gastrectomy & $13(25.5)$ & $64(21.7)$ & - \\
\hline Proximal gastrectomy & $6(11.8)$ & $38(12.9)$ & - \\
\hline Distal gastrectomy & $26(51.0)$ & $149(50.5)$ & - \\
\hline Pylorus-preserving gastrectomy & $6(11.8)$ & $44(14.9)$ & - \\
\hline Reconstruction method, n (\%) & - & - & 0.655 \\
\hline Billroth I & $16(31.4)$ & $93(31.5)$ & - \\
\hline Billroth II & $6(11.8)$ & $20(6.8)$ & - \\
\hline Roux-en-Y & $17(33.3)$ & $109(36.9)$ & - \\
\hline Gastroesophageal & $12(23.5)$ & $73(24.7)$ & - \\
\hline Surgical approach, n (\%) & - & - & $0.016 *$ \\
\hline Laparotomy & $16(31.4)$ & $50(16.9)$ & - \\
\hline Laparoscopic & $35(68.6)$ & $245(83.1)$ & - \\
\hline Extent of lymph node dissection, $\mathrm{n}(\%)$ & - & - & 0.469 \\
\hline$\geq \mathrm{D} 2$ & $27(52.9)$ & $140(47.5)$ & - \\
\hline$<\mathrm{D} 2$ & $24(47.1)$ & $155(52.5)$ & - \\
\hline Duration of operation (min) & $228.3 \pm 37.1$ & $215.6 \pm 33.5$ & $0.014^{*}$ \\
\hline Estimated blood loss (mL) & $420.1 \pm 144.8$ & $406.9 \pm 152.5$ & 0.566 \\
\hline Histopathological grade, n (\%) & - & - & 0.793 \\
\hline GI-2 & $31(60.8)$ & $206(69.8)$ & - \\
\hline G3-4 & $20(39.2)$ & $89(30.2)$ & - \\
\hline Pathological stage, $n(\%)$ & - & - & 0.597 \\
\hline $1 / 11$ & $30(58.8)$ & $185(62.7)$ & - \\
\hline III/IV & $21(4 \mid .2)$ & $110(37.3)$ & - \\
\hline Intra-operative blood transfusion, $\mathrm{n}(\%)$ & - & - & $0.020^{*}$ \\
\hline Yes & II (2I.6) & $30(10.2)$ & - \\
\hline No & $40(78.4)$ & $265(89.8)$ & - \\
\hline Duration of prophylactic antibiotics (d) & $3.6 \pm 0.4$ & $3.5 \pm 0.4$ & 0.100 \\
\hline ICU admission, $n$ (\%) & - & - & 0.280 \\
\hline Yes & $22(43.1)$ & $104(35.3)$ & - \\
\hline No & $29(56.9)$ & $191(64.7)$ & - \\
\hline Oesophageal reflux, n (\%) & $7(13.7)$ & $30(10.2)$ & 0.448 \\
\hline NLR & $2.57 \pm 0.48$ & $2.46 \pm 0.51$ & 0.152 \\
\hline CONUT score, n (\%) & - & - & $0.023 *$ \\
\hline$<4$ & $43(84.3)$ & $276(93.6)$ & - \\
\hline$\geq 3$ & $8(15.7)$ & $19(6.4)$ & - \\
\hline mFI score, $\mathrm{n}(\%)$ & - & - & $<0.001$ \\
\hline$\geq 0.225$ & $20(39.2)$ & $33(11.2)$ & - \\
\hline$<0.225$ & $3 I(60.8)$ & $262(88.8)$ & - \\
\hline
\end{tabular}

Note: $* P$ value $<0.05$ by Chi-square test, $t$-test or Mann Whitney U-test.

Abbreviations: GC, gastric cancer; ASA, American Society of Anesthesiologists; BMI, body mass index; ICU, intensive care unit; NLR, neutrophil-lymphocyte ratio; CONUT, controlling nutrition status; $\mathrm{mFI}$, modified frailty index. 


\section{Distribution of positive items of $\mathrm{mFI}$}

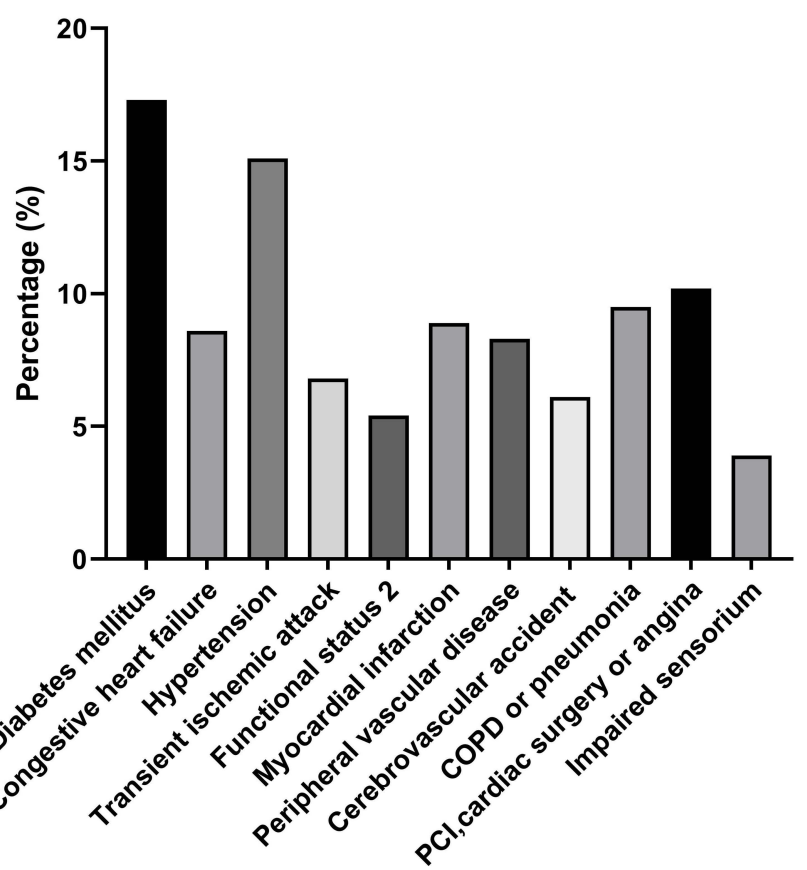

Figure 2 Percentage of positive items of $\mathrm{mFl}$ in total patients.

Abbreviations: $\mathrm{mFI}$, modified frailty index; COPD, chronic obstructive pulmonary disease; $\mathrm{PCl}$, percutaneous coronary intervention.

pulmonary infection on post-operative recovery, perioperative management to decrease the incidence was strongly recommended. Although some previous studies have determined the incidence and risk factors for pulmonary infection, these findings were usually with limited patient sample sizes and variables, which may significantly affect the adequate accuracy. In our multivariate logistic analysis, $\mathrm{mFI}$ was firstly identified as the independent risk factor for postoperative pulmonary infection in elderly GC patients undergoing radical gastrectomy.

Recently, it has been noted that mFI containing 11 items is one of the most common tools to evaluate frailty and $\mathrm{mFI}$ can predict postoperative morbidity and mortality. ${ }^{17,25}$ Studies have indicated that those patients with higher $\mathrm{mFI}$ are accompanied by significantly increased postoperative complications and mortality. ${ }^{29}$ Additionally, mFI containing 11 items can be used to predict postoperative complications and mortality in ICU patients after colectomy. ${ }^{30}$

Recently, a study by Osaki et al reveals that $\mathrm{mFI}$ can predict non-home discharge in elderly GC patients after gastrectomy. ${ }^{31}$ Until now, many studies have supported
Table 2 Preoperative Laboratory Variables Associated with Pulmonary Infection in Elderly GC Patients After Radical Gastrectomy

\begin{tabular}{|c|c|c|c|}
\hline \multirow[t]{2}{*}{ Variables } & \multicolumn{2}{|c|}{ Pulmonary Infection } & \multirow[t]{2}{*}{$P$-value } \\
\hline & $\begin{array}{c}\text { Yes } \\
(n=5 I)\end{array}$ & $\begin{array}{c}\text { No } \\
(n=295)\end{array}$ & \\
\hline Hemoglobin (g/dL) & - & - & 0.595 \\
\hline$\geq 11.0$ & $33(64.7)$ & $202(68.5)$ & - \\
\hline$<11.0$ & $18(35.3)$ & $93(3 \mid .5)$ & - \\
\hline White blood cell $\left(\times 10^{9} / \mathrm{L}\right)$ & - & - & 0.230 \\
\hline $4-10$ & $40(78.4)$ & $251(85.1)$ & - \\
\hline$<4$ or $>10$ & II (2I.6) & 44 (14.9) & - \\
\hline Albumin (mg/dL) & - & - & $0.016 *$ \\
\hline$\geq 35.0$ & $39(76.5)$ & $262(88.8)$ & - \\
\hline$<35.0$ & $12(23.5)$ & $33(1 \mathrm{I} .2)$ & - \\
\hline Creatinine $(\mu \mathrm{mol} / \mathrm{L})$ & - & - & 0.418 \\
\hline$<133.0$ & $48(94.1)$ & $285(96.6)$ & - \\
\hline$\geq 133.0$ & $3(5.9)$ & $10(3.4)$ & - \\
\hline Urea (mmol/L) & - & - & 0.599 \\
\hline$<7.1$ & $4 \mathrm{I}(80.4)$ & $246(83.4)$ & - \\
\hline$\geq 7.1$ & $10(19.6)$ & $49(16.6)$ & - \\
\hline CRP (mg/L) & - & - & $0.012 *$ \\
\hline$<8.0$ & $40(78.4)$ & $267(90.5)$ & - \\
\hline$\geq 8.0$ & II (2I.6) & $28(9.5)$ & - \\
\hline TNF- $\alpha(\mathrm{pg} / \mathrm{mL})$ & - & - & 0.395 \\
\hline$<8.1$ & $45(88.2)$ & 271 (91.9) & - \\
\hline$\geq 8.1$ & $6(11.8)$ & $24(8.1)$ & - \\
\hline
\end{tabular}

Note: ${ }^{*} P$ value $<0.05$ by Chi-square test, or Fisher exact test.

Abbreviations: GC, gastric cancer; CRP, C-reactive protein; TNF- $\alpha$, tumor necrosis factor- $\alpha$.

$\mathrm{mFI}$ as a predictor for postoperative short-term outcomes in patients who underwent vascular, ${ }^{32}$ abdominal, ${ }^{33}$ head and neck surgery. ${ }^{34}$ Nevertheless, mFI could be at least a useful adjunct to predict pulmonary infection in elderly GC patients undergoing radical gastrectomy. Without a doubt, major abdominal surgery is a great challenge for the physiological reserve of elderly patients ${ }^{21}$ and the result that higher $\mathrm{mFI}$ correlate with increased risk of pulmonary infection is not surprising. In recent years, the predictive role of $\mathrm{mFI}$ for postoperative complications has attracted a lot of attention. ${ }^{35}$ A recent study by Chen et al has revealed $\mathrm{mFI}$ as a promising predictor for both postoperative delirium and delayed neurocognitive recovery in elderly subjects after elective total joint arthroplasty. ${ }^{36}$ This present study also provided insight into the association between $\mathrm{mFI}$ and postoperative complications in elderly GC patients, which was in agreement with other 


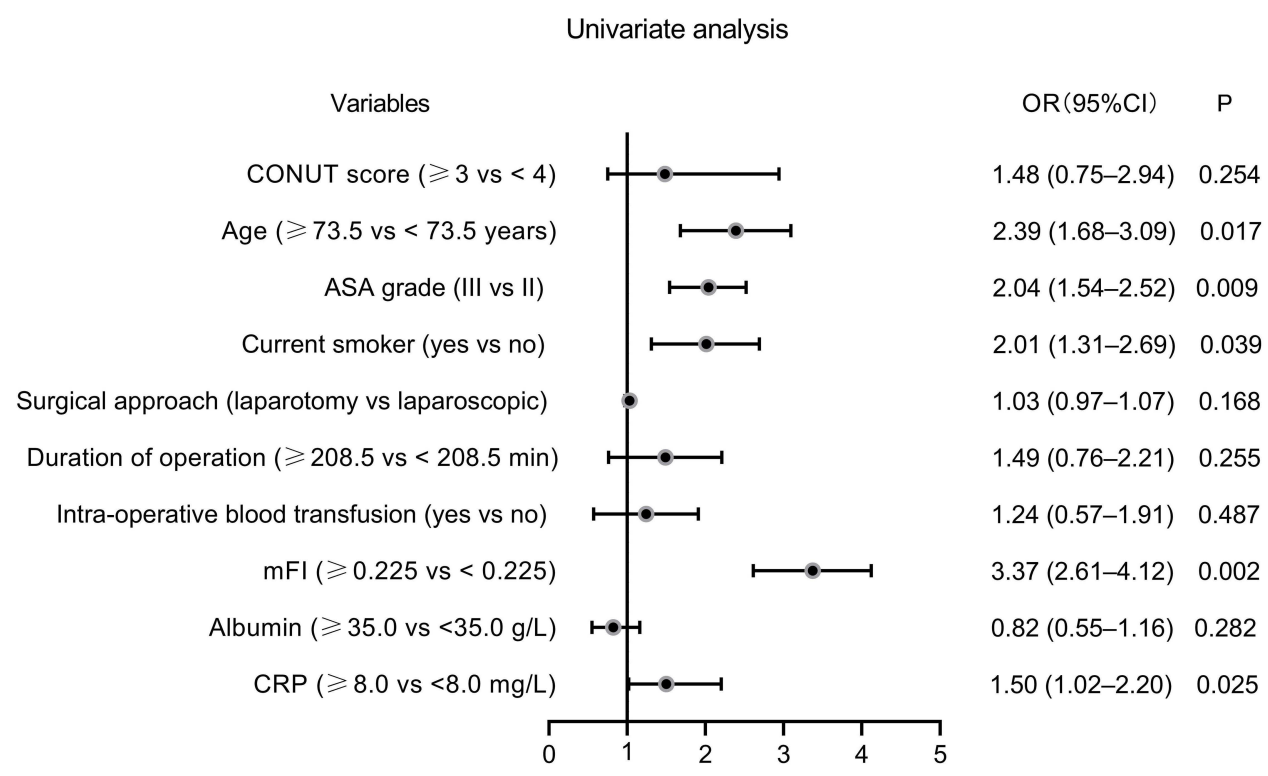

Figure 4 Forest plot of the univariate logistic regression analysis for pulmonary infection.

Abbreviations: ASA, American Society of Anesthesiologists; NLR, neutrophil-lymphocyte ratio; CONUT, controlling nutrition status; mFl, modified frailty index; CRP, C-reactive protein; OR, odds ratio; $\mathrm{Cl}$, confidence interval.

A

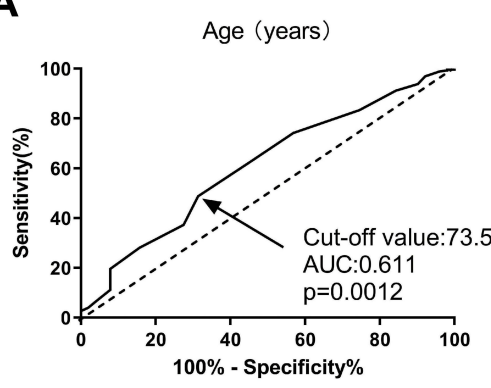

D

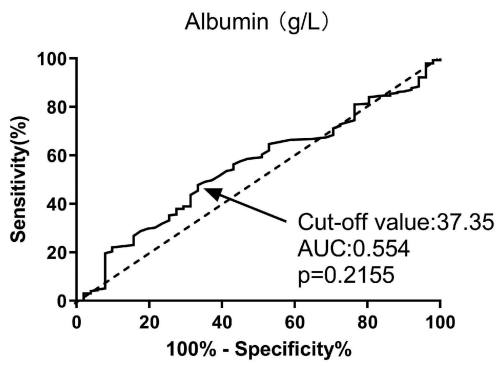

B

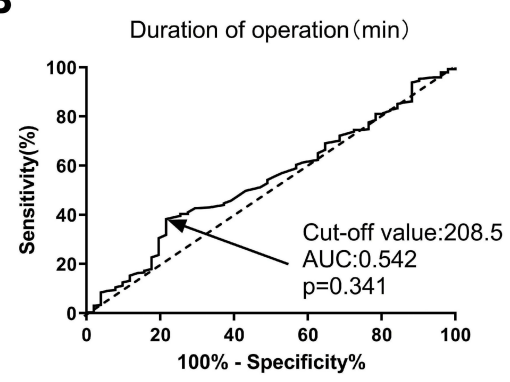

E

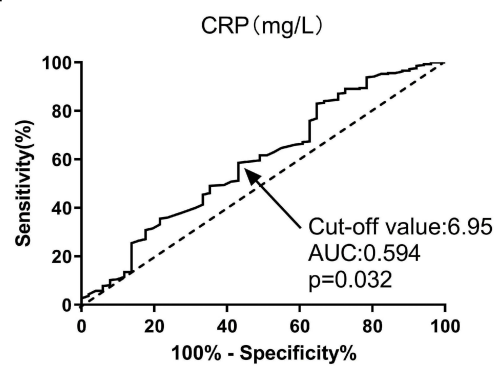

C

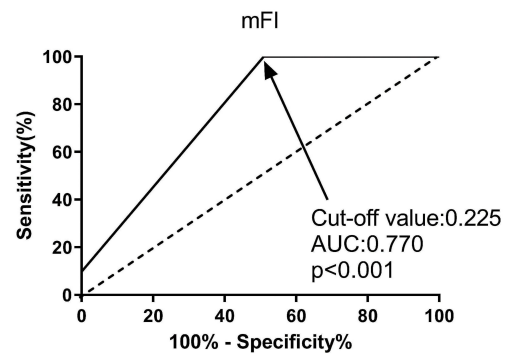

Figure 3 Predictive values of factors for pulmonary infection in elderly GC patients by ROC curve analysis. (A) age; (B) duration of operation; (C) mFI; (D) albumin; and (E) CRP.

Abbreviations: GC, gastric cancer; ROC, receiver operating characteristic; mFI, modified frailty index; AUC, area under the curve; CRP, C-reactive protein.

prior studies. ${ }^{37}$ The frailty is associated with impaired organ functions of the body, decreased ability of the immune system to protect organism against infections. ${ }^{38}$ In addition, diabetes mellitus is an important contributor to the 11-item mFI and it is clearly associated with the increased susceptibility to infection due to various physiopathologic mechanisms. ${ }^{39,40}$ These might be possible explanations for the predictive role of $\mathrm{mFI}$ for 


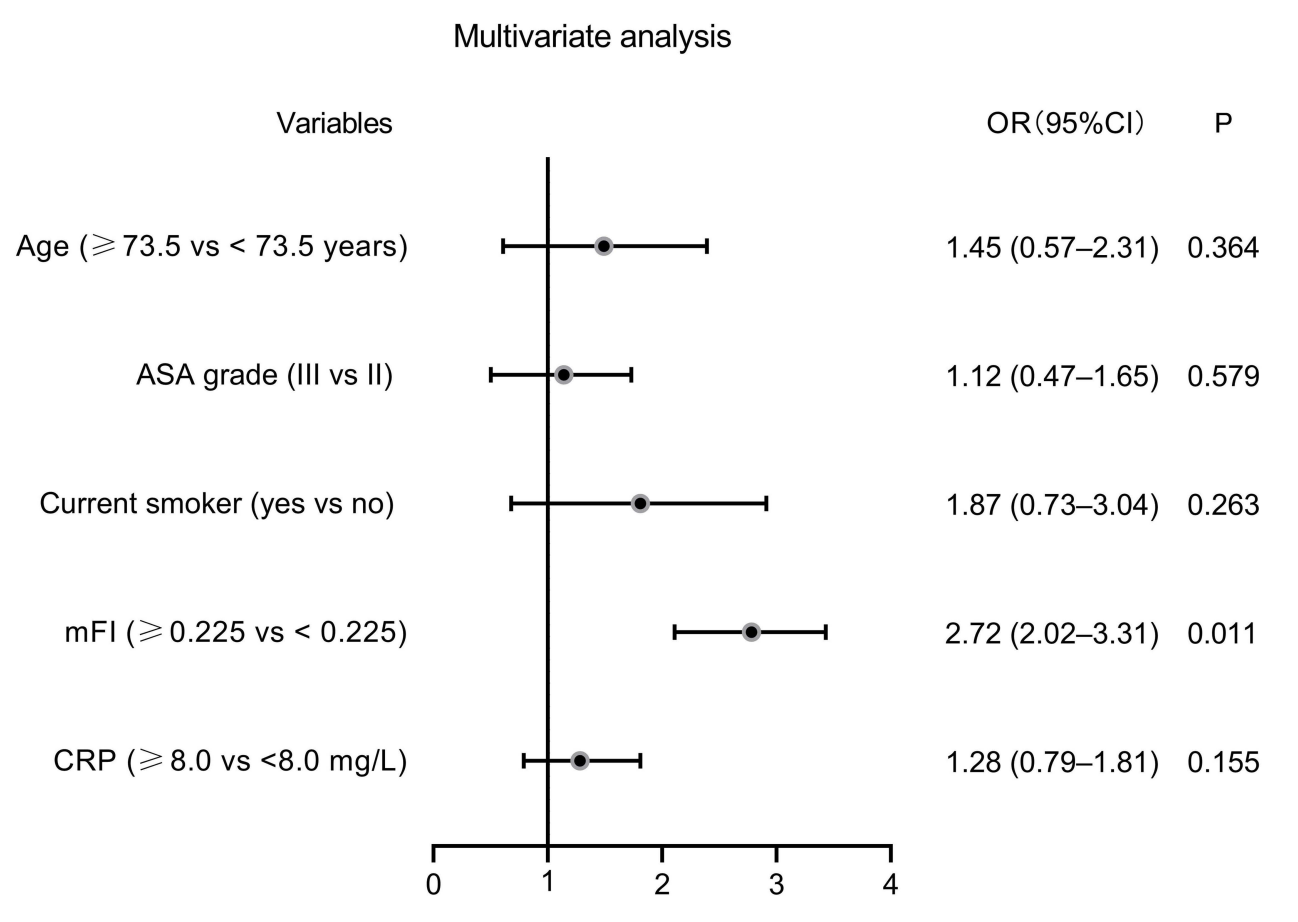

Figure 5 Forest plot of the multivariate logistic regression analysis for pulmonary infection.

Abbreviations: ASA, American Society of Anesthesiologists; mFI, modified frailty index; CRP, C-reactive protein; OR, odds ratio; Cl, confidence interval.

postoperative pulmonary infection. The most common positive item of $\mathrm{mFI}$ in this study was diabetes mellitus. Diabetes is recognized as a well-established risk factor for infection in the general population, ${ }^{41}$ due to impaired immunity, antioxidant systems, and increased susceptibility to bacterial infections. ${ }^{39}$ In addition, another common item, preexisting COPD, was significantly associated with a greater risk of incident pneumonia in the elderly. ${ }^{42}$ These results also provided possible explanations for the role of $\mathrm{mFI}$ in postoperative pulmonary infection.

This study has some limitations to declare. First, this was a single-center study, and its retrospective nature was associated with some bias. For example, the inclusion of patients with other age ranges or immunosuppressive status after preoperative chemoradiotherapy may possibly affect the results. Moreover, dividing the total patients into development and validation groups may minimize the adverse impact of retrospective study and improve the generalizability of the conclusions. Second, the sample size was relatively small and a larger multi-center trial is required to verify our conclusion. It is also needed to use data from other centers to validate the conclusion. Third, the underlying involved mechanisms remain unclear. Moreover, whether other tools for measuring frailty will lead to the same conclusions remain unclear.
In conclusion, our study indicated that $\mathrm{mFI}$ was an independent risk factor for pulmonary infection in elderly GC patients. Moreover, preoperative mFI assessment has the potential to stratify risks and prevent complications. Those patients with higher mFI levels deserved more attention including strict monitoring and timely intervention strategies. In addition, preoperative aggressive controls of some comorbidities (positive items of $\mathrm{mFI}$ ) may possibly be helpful for pulmonary infection prevention.

\section{Data Sharing Statement}

Please contact the corresponding author for data requests.

\section{Ethics Approval and Consent to Participate}

This study was conducted in accordance with the Declaration of Helsinki. All patients included were required to offer written informed consent.

\section{Funding}

There is no funding to report.

\section{Disclosure}

The authors report no conflicts of interest in this work. 


\section{References}

1. Sun LF, Liu K, Su XS, et al. Robot-assisted versus laparoscopicassisted gastrectomy among gastric cancer patients: a retrospective short-term analysis from a single institution in China. Gastroenterol Res Pract. 2019;2019:9059176.

2. Sung H, Ferlay J, Siegel RL, et al. Global cancer statistics 2020: GLOBOCAN estimates of incidence and mortality worldwide for 36 cancers in 185 countries. CA Cancer J Clin. 2021;71(3):209-249. doi: $10.3322 /$ caac. 21660

3. Chou WC, Chang CL, Liu KH, et al. Total gastrectomy increases the incidence of grade III and IV toxicities in patients with gastric cancer receiving adjuvant TS-1 treatment. World $J$ Surg Oncol. 2013;11:287

4. Seo $\mathrm{SH}, \mathrm{Hur} \mathrm{H}, \mathrm{An} \mathrm{CW}$, et al. Operative risk factors in gastric cancer surgery for elderly patients. J Gastric Cancer. 2011;11(2):116-121. doi:10.5230/jgc.2011.11.2.116

5. Kim HH, Hyung WJ, Cho GS, et al. Morbidity and mortality of laparoscopic gastrectomy versus open gastrectomy for gastric cancer: an interim report - a Phase III multicenter, prospective, randomized trial (KLASS Trial). Ann Surg. 2010;251(3):417-420. doi:10.1097/ SLA.0b013e3181cc8f6b

6. Lee JH, Park DJ, Kim HH, Lee HJ, Yang HK. Comparison of complications after laparoscopy-assisted distal gastrectomy and open distal gastrectomy for gastric cancer using the Clavien-Dindo classification. Surg Endosc. 2012;26(5):1287-1295. doi:10.1007/ s00464-011-2027-0

7. Kim JA, Ahn HJ, Oh AR, Choi J. Restrictive intraoperative fluid management was associated with higher incidence of composite complications compared to less restrictive strategies in open thoracotomy: a retrospective cohort study. Sci Rep. 2020;10(1):8449. doi:10.1038/s41598-020-65532-w

8. LaPar DJ, Bhamidipati CM, Lau CL, Jones DR, Kozower BD. The society of thoracic surgeons general thoracic surgery database: establishing generalizability to national lung cancer resection outcomes. Ann Thorac Surg. 2012;94(1):216-21; discussion 21. doi:10.1016/j. athoracsur.2012.03.054

9. Rockwood K, Stadnyk K, MacKnight C, McDowell I, Hebert R, Hogan DB. A brief clinical instrument to classify frailty in elderly people. Lancet. 1999;353(9148):205-206. doi:10.1016/S0140-6736(98) 04402-X

10. Fried LP, Tangen CM, Walston J, et al. Frailty in older adults: evidence for a phenotype. J Gerontol a Biol Sci Med Sci. 2001;56 (3):M146-M156. doi:10.1093/gerona/56.3.M146

11. Winograd $\mathrm{CH}$. Targeting strategies: an overview of criteria and outcomes. $J$ Am Geriatr Soc. 1991;39(9 Pt 2):25S-35S. doi:10.1111/j.1532-5415.1991.tb05930.x

12. Winograd CH, Gerety MB, Chung M, Goldstein MK, Dominguez F Jr, Vallone R. Screening for frailty: criteria and predictors of outcomes. J Am Geriatr Soc. 1991;39(8):778-784. doi:10.1111/ j.1532-5415.1991.tb02700.x

13. Campbell AJ, Buchner DM. Unstable disability and the fluctuations of frailty. Age Ageing. 1997;26(4):315-318. doi:10.1093/ageing/26.4.315

14. Lipsitz LA, Goldberger AL. Loss of 'complexity' and aging. Potential applications of fractals and chaos theory to senescence. JAMA. 1992;267 (13):1806-1809. doi:10.1001/jama.1992.03480130122036

15. Hamerman D. Toward an understanding of frailty. Ann Intern Med. 1999;130(11):945-950. doi:10.7326/0003-4819-130-11-19990601000022

16. Xue QL. The frailty syndrome: definition and natural history. Clin Geriatr Med. 2011;27(1):1-15. doi:10.1016/j.cger.2010.08.009

17. Velanovich V, Antoine H, Swartz A, Peters D, Rubinfeld I. Accumulating deficits model of frailty and postoperative mortality and morbidity: its application to a national database. J Surg Res. 2013;183(1):104-110. doi:10.1016/j.jss.2013.01.021
18. Wachal B, Johnson M, Burchell A, et al. Association of modified frailty index score with perioperative risk for patients undergoing total laryngectomy. JAMA Otolaryngol Head Neck Surg. 2017;143 (8):818-823. doi:10.1001/jamaoto.2017.0412

19. McChesney SL, Canter DJ, Monlezun DJ, Green H, Margolin DA. Modified frailty index predicts postoperative outcomes in patients undergoing radical pelvic surgery. Am Surg. 2020;86(2):95-103. doi: $10.1177 / 000313482008600222$

20. Khalafallah AM, Huq S, Jimenez AE, Brem H, Mukherjee D. The 5factor modified frailty index: an effective predictor of mortality in brain tumor patients. J Neurosurg. 2020:1;1-9.

21. Tatar C, Benlice C, Delaney CP, et al. Modified frailty index predicts high-risk patients for readmission after colorectal surgery for cancer. Am J Surg. 2020;220(1):187-190. doi:10.1016/j.amjsurg.2019.11.016

22. Aceto P, Perilli V, Luca E, et al. Predictive power of modified frailty index score for pulmonary complications after major abdominal surgery in the elderly: a single centre prospective cohort study. Eur Rev Med Pharmacol Sci. 2021;25(10):3798-3802. doi:10.26355/ eurrev 20210525947

23. Japanese Gastric Cancer A. Japanese gastric cancer treatment guidelines 2014 (ver. 4). Gastric Cancer. 2017;20(1):1-19. doi:10.1007/ s10120-016-0622-4

24. Kuroda D, Sawayama H, Kurashige J, et al. Controlling Nutritional Status (CONUT) score is a prognostic marker for gastric cancer patients after curative resection. Gastric Cancer. 2018;21 (2):204-212.

25. Farhat JS, Velanovich V, Falvo AJ, et al. Are the frail destined to fail? Frailty index as predictor of surgical morbidity and mortality in the elderly. J Trauma Acute Care Surg. 2012;72(6):1526-30;discussion 30-1. doi:10.1097/TA.0b013e3182542fab

26. Bluth T, Teichmann R, Kiss T, et al. Protective intraoperative ventilation with higher versus lower levels of positive end-expiratory pressure in obese patients (PROBESE): study protocol for a randomized controlled trial. Trials. 2017;18(1):202. doi:10.1186/s13063-017-1929-0

27. Bluth T, Serpa NA, Schultz MJ, et al.; Writing Committee for the PCGotPVNftCTNotESoA. Effect of intraoperative high Positive End-Expiratory Pressure (PEEP) with recruitment maneuvers vs low PEEP on postoperative pulmonary complications in obese patients: a randomized clinical trial. JAMA. 2019;321 (23):2292-2305. doi:10.1001/jama.2019.7505

28. Yao Z, Yang H, Cui M, et al. [Analysis of risk factors of pulmonary infection in patients over 60 years of age after radical resection for gastric cancer]. Zhonghua Wei Chang Wai Ke Za Zhi. 2019;22 (2):164-171. Chinese

29. Obeid NM, Azuh O, Reddy S, et al. Predictors of critical care-related complications in colectomy patients using the national surgical quality improvement program: exploring frailty and aggressive laparoscopic approaches. J Trauma Acute Care Surg. 2012;72(4):878-883. doi:10.1097/TA.0b013e31824d0f70

30. Vermillion SA, Hsu FC, Dorrell RD, Shen P, Clark CJ. Modified frailty index predicts postoperative outcomes in older gastrointestinal cancer patients. J Surg Oncol. 2017;115(8):997-1003. doi:10.1002/ jso. 24617

31. Osaki T, Saito H, Shimizu S, et al. Modified frailty index is useful in predicting non-home discharge in elderly patients with gastric cancer who undergo gastrectomy. World J Surg. 2020;44(11):3837-3844. doi:10.1007/s00268-020-05691-z

32. Karam J, Tsiouris A, Shepard A, Velanovich V, Rubinfeld I. Simplified frailty index to predict adverse outcomes and mortality in vascular surgery patients. Ann Vasc Surg. 2013;27(7):904-908. doi:10.1016/j.avsg.2012.09.015

33. Louwers L, Schnickel G, Rubinfeld I. Use of a simplified frailty index to predict Clavien 4 complications and mortality after hepatectomy: analysis of the national surgical quality improvement project database. Am J Surg. 2016;211(6):1071-1076. doi:10.1016/j. amjsurg.2015.09.015 
34. Adams P, Ghanem T, Stachler R, Hall F, Velanovich V, Rubinfeld I. Frailty as a predictor of morbidity and mortality in inpatient head and neck surgery. JAMA Otolaryngol Head Neck Surg. 2013;139 (8):783-789. doi:10.1001/jamaoto.2013.3969

35. Lu J, Zheng HL, Li P, et al. High preoperative modified frailty index has a negative impact on short- and long-term outcomes of octogenarians with gastric cancer after laparoscopic gastrectomy. Surg Endosc. 2018;32(5):2193-2200. doi:10.1007/s00464-018-6085-4

36. Chen Y, Qin J. Modified frailty index independently predicts postoperative delirium and delayed neurocognitive recovery after elective total joint arthroplasty. $J$ Arthroplasty. 2021;36(2):449-453. doi:10.1016/j.arth.2020.07.074

37. Garland M, Hsu FC, Shen P, Clark CJ. Optimal modified frailty index cutoff in older gastrointestinal cancer patients. Am Surg. 2017;83 (8):860-865. doi:10.1177/000313481708300837

38. Bellumkonda L, Tyrrell D, Hummel SL, Goldstein DR. Pathophysiology of heart failure and frailty: a common inflammatory origin? Aging Cell. 2017;16(3):444-450. doi:10.1111/acel.12581
39. Joshi N, Caputo GM, Weitekamp MR, Karchmer AW. Infections in patients with diabetes mellitus. $N$ Engl J Med. 1999;341 (25):1906-1912. doi:10.1056/NEJM199912163412507

40. Shah BR, Hux JE. Quantifying the risk of infectious diseases for people with diabetes. Diabetes Care. 2003;26(2):510-513. doi:10.2337/diacare.26.2.510

41. Barone BB, Yeh HC, Snyder CF, et al. Postoperative mortality in cancer patients with preexisting diabetes: systematic review and meta-analysis. Diabetes Care. 2010;33(4):931-939. doi:10.2337/ dc09-1721

42. Ernst P, Gonzalez AV, Brassard P, Suissa S. Inhaled corticosteroid use in chronic obstructive pulmonary disease and the risk of hospitalization for pneumonia. Am J Respir Crit Care Med. 2007;176 (2):162-166. doi:10.1164/rccm.200611-1630OC

\section{Publish your work in this journal}

Cancer Management and Research is an international, peer-reviewed open access journal focusing on cancer research and the optimal use of preventative and integrated treatment interventions to achieve improved outcomes, enhanced survival and quality of life for the cancer patient.
The manuscript management system is completely online and includes a very quick and fair peer-review system, which is all easy to use. Visit http://www.dovepress.com/testimonials.php to read real quotes from published authors. 